\title{
Integrating quantitative and qualitative approaches in psychology research methods teaching: the example of a classroom debate
}

\author{
SALLY WIGGINS ${ }^{1}$ \\ University of Strathclyde, UK \\ SARAH FORREST \\ Nottingham Trent University, UK
}

\begin{abstract}
Research methods teaching in psychology is predominantly divided into quantitative and qualitative modules, often with an emphasis on the former. In this article we argue that by explicitly addressing the integration of methodological approaches we may help to improve students' understanding of psychological research methods overall. The example of a final year module is provided, outlining the use of a student-led classroom debate on the compatibility of qualitative and quantitative methodologies in psychology. This type of learning activity was introduced to encourage a deeper understanding of the module content and to move toward student-centred learning. It is concluded that the relative success of the debate depended largely on the size of the class and the willingness of the students to partake in a non-assessed, planned activity. Suggestions are provided for how the debate could have been better managed, alongside alternative ways in which the whole module may be redesigned.
\end{abstract}

\section{INTRODUCTION}

Research methods teaching within psychology is often polarised into qualitative or quantitative components, whereby different methodologies are taught separately and often with unequal emphases. For example, many psychology courses have a 'statistics' module, with varying degrees of qualitative methods taught in a separate module. Our concern is that the division of such teaching of methods prevents students from engaging with the more fundamental epistemological issues that accompany psychological research methods. We discuss the relative usefulness of a classroom debate in a final year module as being one way in which to encourage both a more critical understanding of the subject matter and a move toward student-centred learning. In this article we outline our own teaching experience of using a debate on mixing methodologies ${ }^{2}$ and provide reflection on the effectiveness of this particular learning activity.

\section{Mixing methodologies and student-centred learning}

The use of polarised research methods teaching has already been documented within the social sciences more generally in the US (Tashakkori and Teddlie, 2003). This trend may also be seen within psychology courses in the UK. The problem with teaching methodologies separately, as Tashaskkori and Teddlie (2003) argue, is that the actual use of methods by researchers often more closely resembles a mixed methods approach (though this is still rather limited; see Todd, Nerlich and McKeown, 2004). That is, the strict qualitative- quantitative dichotomy is broken down in research practice (e.g. Deacon, Bryman and Fenton, 1998; Miles and Huberman, 1994). However, the implementation of these trends into research methods teaching has yet to be fully developed and it is within this context that we highlight our use of a specific learning activity to begin to address these issues.

Our primary aim in using a classroom debate was to encourage a more critical understanding of the issues surrounding the use of mixed methods within psychological research. At the same time, we aimed to encourage a more student-centred approach, through helping to develop independent learning (i.e. through directed reading) and the ability to argue and respond with peers. This move reflects a shift in the literature toward student-centred learning (e.g. Scott, Buchanan and Haigh, 1997), whereby the student is encouraged - and enabled - to play a more active role in their learning experience. This can help to increase student cooperation and motivation on a particular task (see Sharma, Miller and Seth, 1999, for an example) and also encourage critical awareness skills (Lea, Stephenson and Troy, 2003). It aims to move away from surface learning, where students learn by rote, and are not engaging in higher-level cognitive processes, to a deep approach to learning in which students engage meaningfully with the task (Biggs, 1999; Marshall and Rowlands, 1998). Thus, the move toward student-centred learning can be seen to complement the aim of helping develop a deeper, critical understanding of the subject matter.

One way in which student-centred learning can be

\footnotetext{
${ }^{1}$ Correspondence concerning this article should be addressed to the first author at: Department of Psychology, University of Strathclyde, Graham Hills Building, 40 George Street, Glasgow G1 1QE, UK. Email: sally.wiggins@strath.ac.uk.

${ }^{2}$ This debate was used within our teaching practice in a final year research methods module between 2002-4, while we were both teaching in the Psychology Division at Nottingham Trent University.
} 
encouraged is through the use of group work, whereby students are involved in an activity that requires them to work autonomously and alongside fellow students (e.g. Foot and Howe, 1998; Walker, 2001). Using this principle within the teaching of research methods has great potential for encouraging the learning of key methodological skills and understanding. For example, Helman and Horswill (2002) have shown how the use of alternative teaching practices improved the performance of students on a statistics module in psychology. More importantly, perhaps, students enjoyment of the material was increased - and this is particularly significant given the negative responses that can often be seen toward research methods teaching. The inclusion of a debate to allow students to discuss mixed methodologies thus has strong theoretical arguments to support it. Based on group work, but also requiring students to challenge one another, it provides an exciting environment for the development of new arguments and understandings about the subject. In particular, it promotes learning of the theoretical bases on which different methodologies stand.

\section{The research methods module}

Advanced Research Methods (ARM) was a 10-credit final year module of the BSc psychology course at Nottingham Trent University. The module was designed to develop students' understanding of psychological methodologies (building on, and extending, those learnt in the first two years of their degree) and to provide support for their undergraduate projects and beyond. The learning outcomes for the module covered issues of both theoretical understanding and practical application of advanced qualitative and quantitative research methods. The first session of the module addressed some of the broader epistemological issues in psychological research, with the remaining sessions providing the theory and application of a variety of advanced qualitative and quantitative procedures (e.g. discourse analyses, conversation analysis, multiple regression analyses, factor analytic techniques). These sessions were taught as separate units (i.e. first quantitative, then qualitative approaches), though we encouraged students to compare and evaluate each methodology as it was presented.

\section{THE DEBATE}

The debate took place in one of the sessions and was titled: Are qualitative and quantitative methodologies compatible? Each member of the class was assigned, at the start of the module, to one side of the debate. They thus had to argue either 'yes, they are compatible' (the complementary team) or 'no, they are not compatible' (the polarised team). In the first year of running the module, the debate was in the second session. In the second year, we moved it to the final session to allow students more time to develop their ideas about methodology and to conduct their own reading as they studied the module. This proved to be a little more successful in terms of the quality of arguments that were produced.

To summarise, the classroom debate was based on two aims:

- to encourage a critical understanding of the complexity of epistemological and methodological issues in psychology;

- to support a student-centred approach to learning by encouraging independent, guided study on a set topic.

At the start of the debate session we divided the class into the two teams and allowed fifteen minutes for students to rehearse and compile their arguments and to elect a spokesperson. Once this was done, each team took turns to state their three main arguments to support their side in the debate. Following this formal presentation of arguments, the debate was then opened up for a more informal discussion of the points raised, using the spokespersons to field arguments. As lecturers, we acted in a chairing role, though took a back seat to allow the students to manage the discussion as far as possible themselves. This worked quite well, with students mostly talking in turn, and producing reasonable arguments and counter arguments. The main issues raised were the use of triangulation; the incompatibility of theoretical assumptions (e.g. social constructionism vs positivism); the limitations of using a single methodology; and the practicalities and problems of using different methodologies on a data sample. The students also found it helpful to provide examples, and indeed, this appeared to be a critical feature of the debate; it was difficult to discuss in the abstract without having concrete examples to consider in more depth. The majority of students who attended the debates did seem to enjoy the task and only a minority did not participate at all. Those who did not have the confidence to speak out in the actual debate generally contributed some of their own findings when the teams were collating their arguments.

In sum, the debate included a range of appropriate and thoughtful arguments on the topic of integrating research methodologies. However, there were points that students found more difficult to grasp. For example, methods (e.g. using interviews) were often confused with methodologies (e.g. discourse analysis) and students often did not take epistemological issues to their full conclusions. For instance, they seemed to be aware that social constructionism usually demands more qualitative approaches, but not that this might also preclude combining these with statistical analyses (and why this might be the case). 


\section{EVALUATION OF THE DEBATE}

We evaluated the debate with respect to the two aims under which it was devised.

\section{Encouraging a critical understanding of methodological issues in psychology}

An important part of this exercise was to encourage students to think more critically about methodological issues within psychology; for example, examining how epistemology relates to methodology, and validity and reliability claims in research findings (see also Wise, 2003, for another example of engaging students in research methods learning). Peer interaction, more generally, has already been highlighted as a means by which to develop critical thinking skills (Anderson and Soden, 2001; Rimiene, 2002). In particular, environments that involve a high level of student-student and teacher-student dialogue are thought to encourage a deep understanding of material (Anderson et al., 2001; Nicol and Boyle, 2003). The use of the student-led debate was based on such principles, but also required students to be more active in guiding and framing the discussion. They were required to manage their own understanding of material during the learning session. That is, while they may develop their understanding outside the classroom, once in the debate they were in a situation where their understanding could be either challenged or affirmed. The debate thus provided ideal conditions under which to stimulate critical thinking skills - to reflect on their understanding - and at times during the session there was evidence of students really engaging with the material while they argued their case. Examples of specific research designs they had read about were used as evidence for one team or the other and these were particularly useful in terms of developing arguments or challenging claims.

In many ways we found the debate useful in terms of providing a balance between encouraging students to interact and think critically about a topic and ensuring that the learning objectives for the whole module are met. Hearing the students discuss key issues aloud with their peers is a useful way of assessing, on the spot, whether or not they have grasped the key points. Moreover, this allows an alternative means by which students can express themselves, and is of great benefit to those who find it hard to make themselves clear through the conventional written media of exams and coursework. However, there are limitations to how much we can surmise from the debate alone. Written and verbal feedback from the students at a later time did confirm the enjoyment and usefulness of the debate, though the level of critical understanding of the material was harder to measure. It would seem appropriate, therefore, to add in a means of evaluating the 'success' of the debate in these terms in future. This might involve assessment during or following the debate, for instance.

\section{Supporting student-centred learning}

Our aim to encourage students to develop their own skills in researching topics and evaluating material - a goal of student-centred learning - was met to a limited extent. It was noticeable that some students had prepared well for the debate, bringing notes and making reference to specific parts of textbooks that were relevant to the discussion. While this is not the only evidence of independent learning, it was useful in providing an indicator of this, and it further endorsed the seriousness of the task for the other students. On the other hand, it was important to make this an enjoyable task for students, to help increase motivation (Reynolds, 1994). Such learning activities also have an educational advantage, as well as a motivational one, as students are able to learn from each other as well as from the tutor. Seeing fellow students engaging in the debate, and hearing their arguments, helped to create a sense of knowledge as being accessible and understandable.

Encouraging students to become more independent in the learning process is one step toward learner autonomy where the control and responsibility of learning lies with the student (see Chan, 2001, for a more detailed discussion of this concept). In the preparation for the classroom debate, students were responsible for both the amount and content of material that they researched. However, it is accepted that the incentive to carry out this work may have been small. The students knew that the task was not being assessed (in fact, this was explicitly raised as an issue on a few occasions by the students themselves on questioning the rationale for the task) and there were no obvious benefits for doing any preparation for the discussion. So this raises a broader issue of assessment and the learning experience: how do we deal with the pressures of assessment where tutors are trying to encourage deep learning (Norton et al., 2001)? While the students seemed to enjoy and benefit from the experience of the debate, those who did not see the point simply did not attend the session or took no active part in the discussion.

Resistance to student-centred approaches to learning has been documented already (Lea et al., 2003; Peeke, 1993) and we noted similar responses in some of our students with regard to the debate. Ironically, the lack of assessment - while being one of the factors that possibly led to the encouragement of students to get involved - was cited by some students as being a reason for not spending any time in preparation for the debate. This may have been due to the pressures on students in their final year, as assessments and undergraduate projects become more demanding, to prioritise their time in terms of what will count toward their final degree classification. However, we were also aware that students seemed less willing to take responsibility for their studies at different times in the module. The success of the student debate, therefore, depends on earlier procedures being put into 
place to support a wider acceptance of student-centred approaches to learning.

\section{REFLECTIONS AND CONCLUSIONS}

Overall, we felt that the use of a debate as a learning activity within a research methods module met our aims to a limited extent, with it being more useful in promoting critical understanding than in supporting student-centred learning. As noted above, this is due in part to its limitations as a single component part of the module. For example, the debate is unlikely in itself to persuade students that qualitative and quantitative methodologies can be compatible. Indeed, the use of two lecturers to teach the separate parts of the module was itself reifying the dichotomy of the two paradigms (see also Hopkinson and Hogg, 2004). To avoid this, the entire module would need to be reworked to provide a more integrated approach. For example, Tashakkori and Teddlie (2003) outline a module that covers the research process stepby-step, and highlights the mixed methods possibilities at each step. Alternatively, a replacement of all lectures with small group tutorials and workshops, such as that reported in Scott et al. (1997) might help to encourage more independent learning. However, such a change requires considering other issues, such as assessment and the location of the module within research methods provision across all year groups.

On the basis of our experience of using the debate as a single session within research methods teaching in psychology, we would recommend the following:

- the debate works best for small numbers, so large classes could be divided up. Alternatively, a number of students could be picked out to perform the debate with the remaining students as observers and providing some of the arguments;

- incorporate shorter, more frequent debates into the module design (Anderson and Soden, 2001, make a similar point about peer interaction generally). This would help to develop students' argumentative skills and assist them in engaging more deeply with the module material. Some measures would have to be put in place to avoid the debates just becoming another small group discussion;

- provide concrete examples for students to focus on (or allow them to choose their own). These might best be linked to work in other modules, or to students' own work (such as final year dissertations), to make the topic more relevant to course issues.

- provide examples of the sorts of arguments that can be used. This might be done through a preparatory session, where the two teams view the key arguments prepared by the other team. This would allow them the opportunity to devise counter-arguments or questions to probe their assumptions further. Examples of arguments or questions could be: 'How would you combine conflicting theoretical approaches?'; 'What would we know about a phenomenon through using different methodologies?'; 'How would you actually combine different methodologies in practice?';

- the debate requires a depth of knowledge of research methods that might not be available to first or second year students. Hence, this learning activity will probably work best with more advanced students, particularly if they are working on their own research projects or dissertations;

- incorporate some form of assessment of the debate, to improve student participation. An example would be to use peer- and self-assessment, whereby marking criteria are produced collaboratively by students and tutor, and students must then grade their own and others' performance on factors such as coherence, depth and quality of argument. Involving students in the production of criteria should help to increase motivation and comfort in the assessment process (Brown, Race and Rust, 1995) and also contribute toward a more student-centred approach.

A more radical recommendation to encourage student-centred learning more broadly would involve the redesign of the research methods module as a whole. An example of this can be seen in Benson and Blackman's (2003) discussion of their development of a final year research methods module within a business school. Here, they discuss the redesign of the module to link more closely with the development of students' undergraduate dissertations, using an activity-based approach (thus involving the students more closely in the learning process). An alternative idea may be developed from Harlos et al. (2003) use of a panel session to allow for a deeper consideration of how qualitative approaches might be compared when analysing sample data. This used three lecturers (each specialising in one methodology), and a group of students discussing and reflecting on the use of different methodologies for the analysis of the sample data. While this had a qualitative focus, one might develop this to consider the potential for mixed methodologies in psychological research. While both of these studies provide interesting examples for methods teaching, they offer a more radical overhaul of module structures than may be necessary to incorporate debate or critical discussion elements.

In conclusion, we found the student-led debate to be a particularly useful component of our research methods teaching, as it encouraged critical understanding of methodological issues and provided a move toward student-centred learning. In particular, it is helpful in deepening students' understanding of research methods 
overall, and encouraged thinking beyond the qualitative and quantitative dichotomy. However, it does require some preparation and further structuring to strengthen its usefulness and a reconsideration of the value of student-centred learning within research methods teaching in general.

\section{ACKNOWLEDGEMENTS}

We would like to thank the final year students involved in this module for their feedback and two anonymous reviewers for their invaluable comments on an earlier version of this paper.

\section{REFERENCES}

Anderson, T., Howe, C., Soden, R., Halliday, J. and Low, J. (2001). Peer interaction and the learning of critical thinking skills in further education students. International Science, 29, 1-32.

Anderson, T. and Soden, R. (2001). Peer interaction and the learning of critical thinking skills. Psychology Learning and Teaching, 1, 37-40.

Benson, A. and Blackman, D. (2003). Can research methods ever be interesting? Active Learning in Higher Education, 4, 39-55.

Biggs, J. (1999). Teaching for quality learning at university. Buckingham: Open University Press.

Brown, S., Race, P. and Rust, C. (1995). Using and experiencing assessment. In P. Knight (Ed.) Assessment for learning in higher education (pp. 75-85). London: Kogan Page.

Chan, V. (2001). Learning autonomously: the learners' perspectives. Journal of Further and Higher Education, 25, 85-300.

Deacon, D., Bryman, A. and Fenton, N. (1998). Collision or collusion? A discussion of the unplanned triangulation of quantitative and qualitative research methods. International Journal of Social Research Methodology, 1, 47-64.

Foot, H. and Howe, C. (1998). The psychoeducational basis of peer-assisted learning. In K. Topping and S. Ehly (Eds.) Peer assisted learning (pp.27-43). London: LEA.

Harlos, K. P., Mallon, M., Stablein, R. and Jones, C. (2003). Teaching qualitative methods in management classrooms. Journal of Management Education, 27, 304-322.

Helman, S. and Horswill, M. S. (2002). Does the introduction of non-traditional teaching techniques improve psychology undergraduates' performance in statistics? Psychology Learning and Teaching, 2, 12-16.

Hopkinson, G. C. and Hogg, M. K. (2004). Teaching and learning about qualitative resarch in the social sciences: an experiential learning approach amongst marketing students. Journal of Further and Higher Education, 28, 307-320.
Lea, S. J., Stephenson, D. and Troy, J. (2003). Higher education students' attitudes to student-centred learning: beyond 'educational bulimia'. Studies in Higher Education, $28,321-334$.

Marshall, L. and Rowlands, F. (1998). A guide to learning independently (3rd edition). Melbourne, Australia: Longman.

Miles, M. and Huberman, M. (1994). Qualitative data analysis: an expanded sourcebook (2nd edition). Thousand Oaks, CA: Sage.

Nicol, D. J. and Boyle, J. T. (2003). Peer instruction versus class-wide discussion in large classes: a comparison of two interaction methods in the wired classroom. Studies in Higher Education, 28, 457-473.

Norton, L. S., Tilley, A. J., Newstead, S. E. and FranklynStokes, A. (2001). The pressures of assessment in undergraduate courses and their effect on student behaviours. Assessment and Evaluation in Higher Education, 26, 269-284.

Peeke, G. (1993). Issues and problems in implementing student centred learning with adults. Journal of Teacher Development, 2, 46-52.

Reynolds, M. (1994). Groupwork in education and training: ideas in practice. London: Kogan Page.

Rimiene, V. (2002). Assessing and developing students' critical thinking. Psychology Learning and Teaching, 2, 7-22.

Scott, J., Buchanan, J. and Haigh, N. (1997). Reflections on student-centred learning in a large class setting. British Journal of Educational Technology, 28, 19-30.

Sharma, M. D., Millar, R. and Seth, S. (1999). Workshop tutorials: accommodating student-centred learning in large first year university physics courses. International Journal of Science Education, 21, 839-853.

Tashakkori, A. and Teddlie, C. (2003). Issues and dilemmas in teaching research methods courses in social and behavioural sciences: US perspective. International Journal of Social Research Methodology, 6, 61-77.

Todd, Z., Nerlich, B. and McKeown, S. (2004). Introduction. In Z. Todd, B. Nerlich, S. McKeown and D. D. Clarke (Eds.) Mixing methods in psychology: the integration of qualitative and quantitative methods in theory and practice (pp. 3-16). Hove: Psychology Press.

Walker, A. (2001). British psychology students' perceptions of group-work and peer assessment. Psychology Learning and Teaching, 1, 28-36.

Wise, A. (2003). Web-based puzzle program to assist students' understanding of research methods. Active Learning in Higher Education, 4, 93-202.

Manuscript received on 23 March 2004

Revision accepted for publication on 19 January 2005 